\title{
Comparison of Emotional Intelligence Scores among Engineering Students at Different Stages of an Academic Program
}

\author{
Nizaroyani Saibani ${ }^{1,2}$, Mohamed Idham Sabtu ${ }^{2}$, Norhamidi Muhamad ${ }^{2}$, Dzuraidah Abd Wahab ${ }^{2}$ Jaafar Sahari $^{2}$ \\ \& Baba Md. Deros ${ }^{2}$ \\ ${ }^{1}$ Centre for Engineering Education Research, Universiti Kebangsaan Malaysia, Selangor, Malaysia \\ ${ }^{2}$ Department of Mechanical \& Materials Engineering, Faculty of Engineering \& Built Environment, Universiti \\ Kebangsaan Malaysia, Selangor, Malaysia \\ Correspondence: Nizaroyani Saibani, Department of Mechanical \& Materials Engineering, Faculty of \\ Engineering \& Built Environment, Universiti Kebangsaan Malaysia, 43600 UKM Bangi, Selangor, Malaysia. Tel: \\ 60-3-8921-6523. E-mail: nizar@eng.ukm.my
}

Received: September 24, 2012 Accepted: November 7, $2012 \quad$ Online Published: November 30, 2012

doi:10.5539/ass.v8n16p88 URL: http://dx.doi.org/10.5539/ass.v8n16p88

\begin{abstract}
Intelligence quotient (IQ) has been widely used as a measure of an individual's intellectual abilities. Emotional intelligence or emotional quotient (EQ) is equally important in defining excellent work performance. An increasing number of employers have started considering fresh graduates with high EQ because the job market is already full of academically competent candidates. With this motivation considered, this study aims to compare the EQ levels of four groups of undergraduate students in their first year of enrollment in their academic program and at the start of each succeeding academic year in the Faculty of Engineering and Built Environment, Universiti Kebangsaan Malaysia (UKM). The EQ scores of these students were also monitored until their graduation. The EQ levels were determined using the Malaysian EQ Inventory (MEQI) test developed by UKM researchers. A comparative study of EQ levels among five batches of students was conducted, starting from their first enrollment in their respective programs. One batch of students has completed the study, and their MEQI results indicated a slight reduction in the total EQ scores. However, two domains recorded improvement: social skills and maturity. Thus, tertiary education is not expected to change student EQ levels, completely because EQ level comprises cognitive and emotional qualities developed during primary and secondary years of education. Innovative strategies on effective teaching and learning activities should be identified to determine their positive influence on the development of EQ domains.
\end{abstract}

Keywords: emotional intelligence, engineering and built environment students, Malaysian EQ inventory tests

\section{Introduction}

Intelligence quotient (IQ) has been widely used in measuring the level of work performance of an individual. People with high IQ test scores are normally considered highly intelligent. However, success in life does not consist solely of high IQ. In addition to mental capability, many other elements constitute a healthy and fulfilling life. One of the elements that have been increasingly recognized is emotional quotient (EQ). This measure has been associated with the traits of outstanding and successful corporate leaders, entrepreneurs, and individuals. Exceptional skills in communication and social interaction are among the qualities of people with high EQ and undoubtedly contribute toward developing a desirable personality. Unlike IQ, EQ continues to develop with life experiences and relates to leadership potential, which is considered by many as a barometer of excellence in virtually any undertaking. Therefore, EQ becomes an interesting element associated with the academic performance of students in tertiary education. The students' years of experience at their previous educational institutions may have a gradual effect on their EQ development.

Some people argue that academic performance relies solely on IQ level as a measure of intelligence. However, EQ affects the ability to use intelligence because EQ provides the foundation for self-appraisal and self-expression, as well as the appraisal of emotion in others. An education system that widely practices outcome-based learning, assessment methods that combine the cognitive, affective, and psychomotor domains are commonly used to measure overall student performance. A number of studies have been conducted on EQ models and conceptual framework development. Salovey and Mayer (1990) first used the term "emotional 
intelligence" and concluded that it consists of three categories of adaptive abilities: appraisal and expression of emotion, regulation of emotion, and utilization of emotion in solving problems. Appraisal and expression of emotion is divided into verbal and nonverbal components. The latter is further classified into nonverbal perception and empathy with other people. Regulation of emotion consists of emotional self-regulation and emotional regulation in others. Utilization of emotion in solving problems includes flexible planning, creative thinking, as well as redirected attention and motivation. This third category can be considered related to student's course assessment. This EQ model by Salovey and Mayer focuses not only on emotions but also on the effect of the use of emotions. Specific-ability models provide ways through which emotions facilitate thinking. For example, emotions may prioritize thinking (Mandler 1975) or allow people to improve their decision-making skills (Lyubomirsky et al. 2005). The concepts underlying these models support the idea that EQ can develop an individual into a successful leader or manager, which is highly desirable in a work environment. Therefore, focusing on increasing the EQ level of students in tertiary education can increase students' marketability after graduation.

EQ can help students experience a successful and happy life beyond education. Other EQ models stress varying degrees of combination in other scales of happiness, stress tolerance, and self-regard (Bar-On 1997); adaptability, (low) impulsiveness, and social competence (Boyatzis \& Sala 2004, Petrides \& Furnham 2001); and creative thinking, flexibility, and intuition versus reason (Tett et al. 2005). The pressure to fulfill and achieve high academic requirements can be overwhelming. Thus, students must be adequately skilled to manage and control pressure. EQ continues to be associated with the criteria for academic and social success after controlling personality and intelligence measure (Van der Zee, Thijs, \& Schakel 2002). Janovics and Christiansen (2001) reported a positive result in job performance by using measures of EQ trait and ability. Some EQ tests were conducted based on previous research. For example, Schmidt-Atzert and Buhner (2002) conducted the "Test of Emotional Intelligence," which covers the ability to perceive accurately and appraise emotion in others, as well as the ability to understand emotion. Prakash, Peter, and Raj (2007) suggested that EQ is not opposed to IQ but rather, acts as an extension of human potential to succeed in a people-oriented environment. Traditional cognitive intelligence or IQ is combined with noncognitive intelligence or EQ to help leaders, especially those in education, to perform most efficiently and inspire others to become successful and happy.

EQ is equally important in defining an excellent work performance. An increasing number of employers have started to consider fresh graduates with high EQ because the job market is already full of academically competent candidates. With this motivation considered, this study aims to compare the EQ levels of undergraduate students at the start of their academic program with their EQ levels at the start of each succeeding academic year in the Faculty of Engineering and Built Environment at the Universiti Kebangsaan Malaysia (UKM). A comparative study of EQ levels among five batches of students was conducted, starting from their first enrollment in their programs.

\section{Methods and Materials}

This study uses the Malaysian EQ Inventory (MEQI) test to analyze the relationship (effectiveness) of the domains constituting the EQ model in measuring EQ levels. This study involves undergraduate students in the Faculty of Engineering and Built Environment at UKM. MEQI was developed by UKM researchers (Noriah \& Zuria, 2003) to incorporate Malaysian values and characteristics. The findings validated the five domains suggested by Goleman (1995). These domains include self-awareness, self-regulation, self-motivation, empathy, and social skills. However, the five domains were found inadequate to describe emotional intelligence among Malaysian individuals. The reseachers proposed incorporating two additional domains, spirituality and maturity, into the development of MEQI. This proposed model addresses the traditional Malaysian culture, which values respect for elders and embraces spirituality in many aspects of life.

Every domain consists of closely related subdomains. For example, the self-regulation domain includes self-control, trustworthiness, responsibility, adaptability, and innovation as subdomains. Self-control responds to keeping disruptive emotions and impulses in check, trustworthiness responds to maintaining a standard of honesty and integrity, responsibility refers to accountability for personal performance, adaptability provides flexibility in handling change, and innovation familiarizes respondents to novel ideas, approaches, and information. The division into one or more subdomains broadens the scope encompassed by the domain.

This study uses the MEQI as a tool to assess the EQ levels of engineering students. This study also examines the lacking domains among students and determines how to improve domain levels. Thus far, the academic performance of students is not associated with any EQ study. Consequently, no EQ levels of related students have been reported. This study is in its early stages; thus, its sole objective is to assess all EQ domains during 
course enrollment and completion. Each student took the test online and the scores relative to the seven domains were obtained. The subdomains under each domain are listed in Table 1.

Table 1. Subdomains of the MEQI model

\begin{tabular}{|c|c|c|c|}
\hline Domain & Subdomain & Domain & Subdomain \\
\hline 1) SELF-AWARENESS & $\begin{array}{c}\text { emotional awareness } \\
\text { accurate self-assessment } \\
\text { self-confidence } \\
\text { honesty }\end{array}$ & 2)SELF-REGULATION & $\begin{array}{c}\text { self-control } \\
\text { trustworthiness } \\
\text { responsibility } \\
\text { adaptability } \\
\text { innovation }\end{array}$ \\
\hline 3) SELF-MOTIVATION & $\begin{array}{l}\text { achievement drive } \\
\text { commitment } \\
\text { initiative } \\
\text { interest }\end{array}$ & 4) ЕМРАТНY & $\begin{array}{l}\text { understanding others } \\
\text { helping others } \\
\text { leveraging diversity } \\
\text { service orientation } \\
\text { developing other's } \\
\text { potential } \\
\text { political awareness }\end{array}$ \\
\hline 5) SOCIAL SKILLS & $\begin{array}{c}\text { influence } \\
\text { conflict management } \\
\text { leadership } \\
\text { change catalyst } \\
\text { building bonds } \\
\text { collaboration and } \\
\text { cooperation } \\
\text { team capabilities } \\
\text { communication }\end{array}$ & 7) MATURITY & \\
\hline
\end{tabular}

MEQI is developed as an online system that allows respondents to answer all questions in 45 minutes. MEQI is available in two versions: MEQI-A and MEQI-D. MEQI-A is administered to students who are still within the educational environment, whereas MEQI-D is administered to individuals applying for jobs or already employed. The test can be taken in Bahasa Malaysia, English, Mandarin, and Korean. The test results are entered into a database and compared with the norm to generate a profile report. This comparison can help respondents identify areas for improvement and chart their soft skills developmental plan. Possible intervention can also be initiated for monitoring and identifying candidates for recruitment, promotion, scholarship awards, or leadership development. Figure 1 presents the flow of the MEQI process involved.

This study begins with a report on the EQ scores of students obtained during their first enrollment. Five batches of UKM engineering and architecture students (a total of 721 students) were compared. Tests were conducted among first year students from five academic sessions: 2006/2007, 2007/2008, 2008/2009, 2009/2010, and 2010/2011. Tests were also conducted in 2011 among the students who enrolled in the second, third, and fourth academic years, which was the second time for these students to take the MEQI test. One batch (2007/2008) of students also took the test in 2011, representing the exit level. This batch, who graduated in September 2011, took the test online prior to graduation. A total of 99 out of 359 graduating students took the test, thus yielding a $27.58 \%$ response rate. 


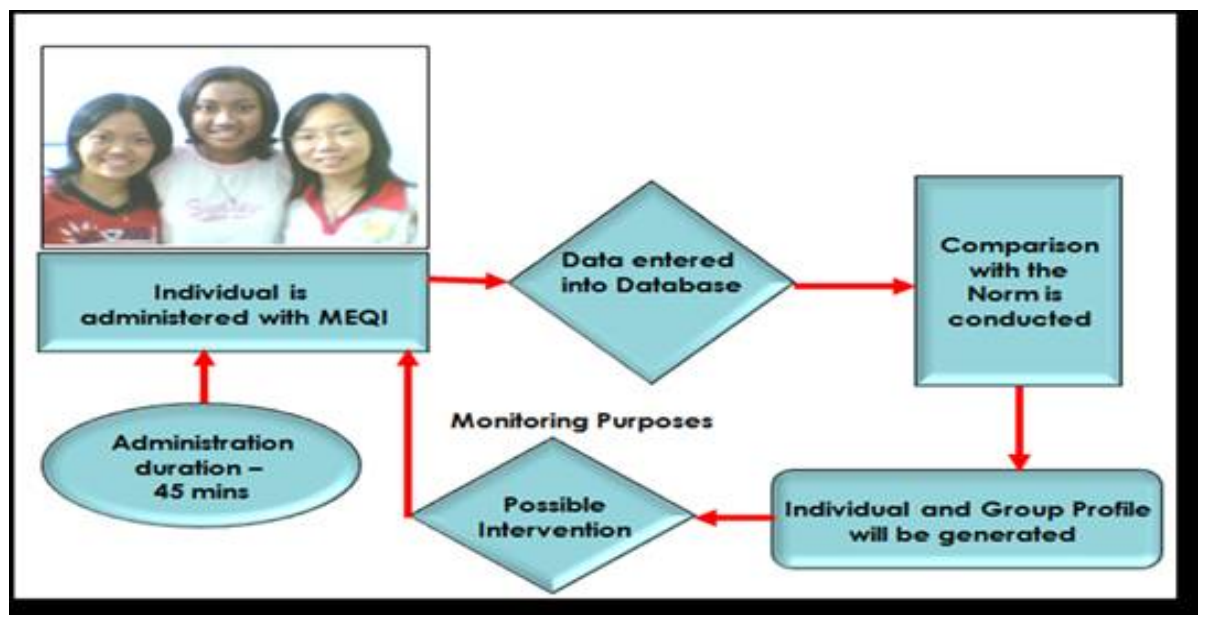

Figure 1. Flow diagram of the MEQI process

\section{Results and Discussion}

The results represent the data collected from the four groups of students. The first group of data represents the comparison between the MEQI scores of the first year students in their first year of enrollment in and their MEQI scores in their final year of completing the course and close to graduation. As presented in Figure 2, only two domains showed increments in MEQI percentage. Social skills achieved the highest increment (17.35\%), and maturity recorded a slight increment. The remaining five domains exhibited a percentage reduction. Self-awareness domain obtained the highest decrement (12.17\%).

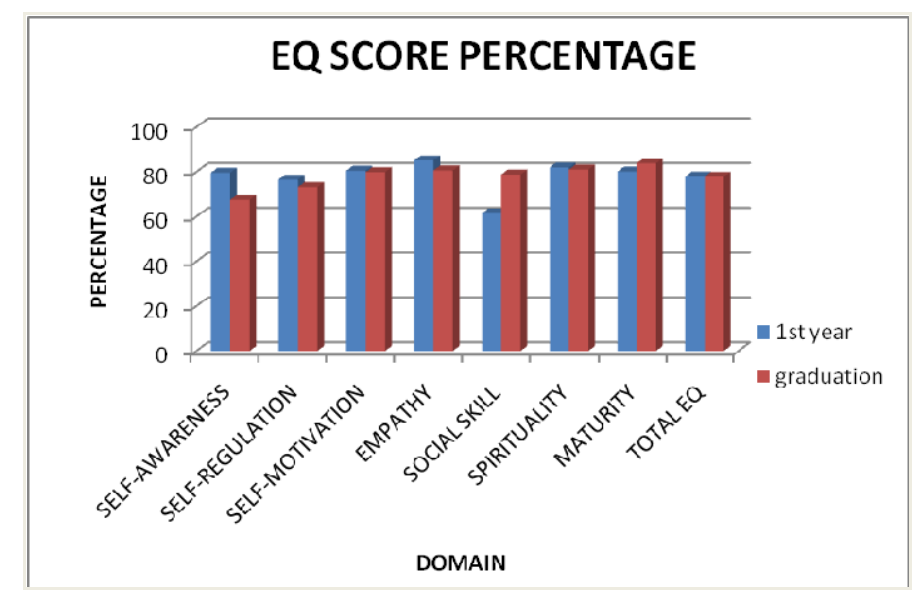

Figure 2. Comparison between the EQ percentage of students who have completed their four-year academic program and their EQ percentage in their first year of enrollment

The second group of data shows the comparison between the EQ percentage of the fourth year students in their first year of enrollment and their EQ percentage in their fourth year of enrollment. As presented in Figure 3, self-regulation achieved the highest increment $(0.24 \%)$ in EQ percentage. Maturity exhibited the highest decrement $(3.30 \%)$. The remaining five domains showed a percentage reduction. 


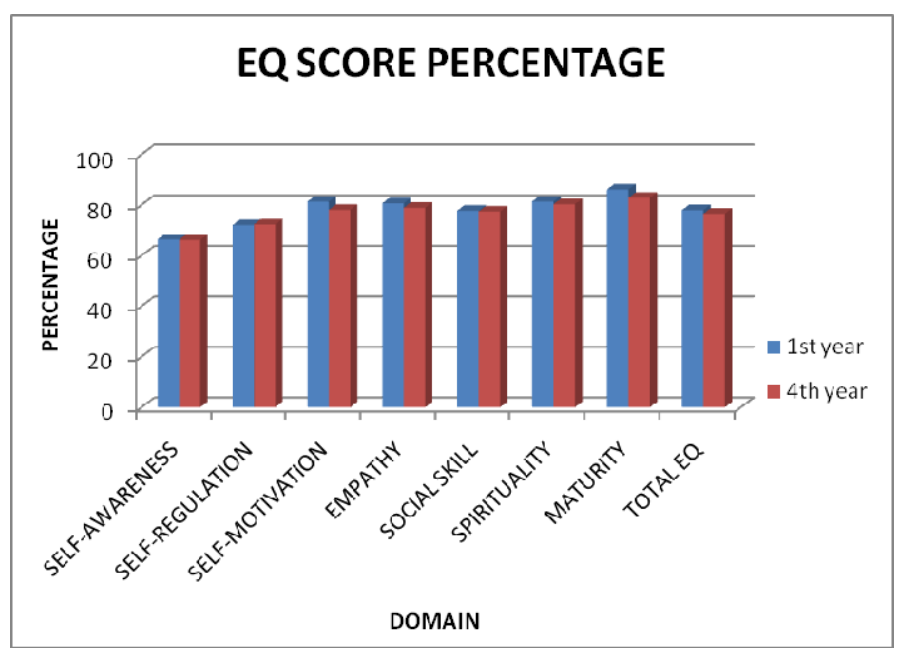

Figure 3. Comparison between the EQ percentage of the fourth year students and their EQ percentage in their first year of enrollment

For the third group of data, the EQ percentage of the third year students in their first year of enrollment in the course were compared with the EQ percentage obtained in their third year of enrollment. Figure 4 shows that social skills achieved the highest increment $(0.84 \%)$, whereas maturity exhibited the highest decrement $(1.70 \%)$ in EQ percentage. Spirituality indicated no change in percentage. Self-regulation showed a reduction, whereas the three remaining domains recorded slight percentage increases.

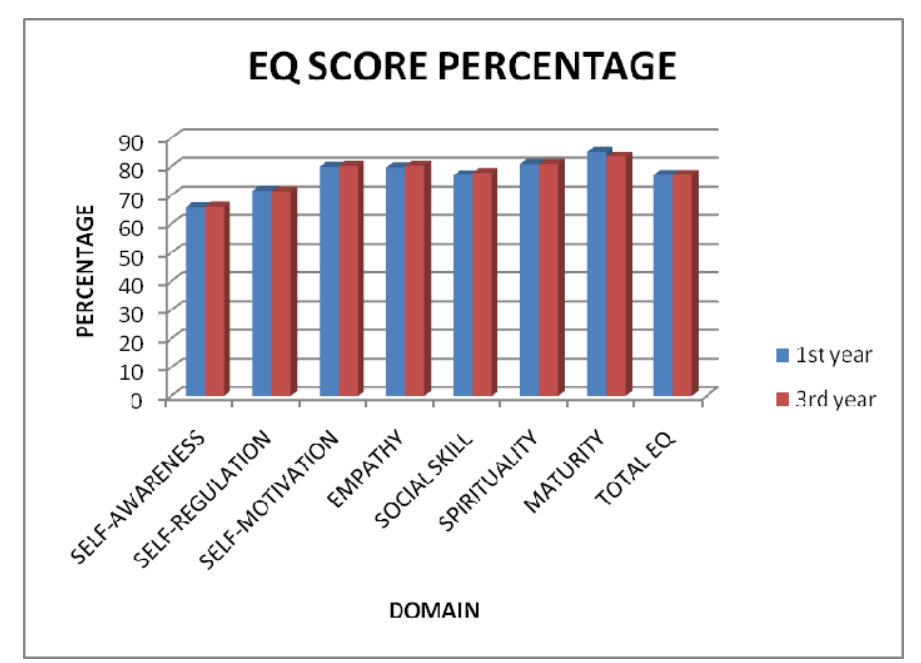

Figure 4. Comparison between the EQ percentage of the third year students in their first year of enrollment and their EQ percentage in their third year of enrollment

The fourth group of data presents a comparison between the EQ percentage of the second year students in their first year of enrollment and their EQ percentage in their second year of enrollment. Figure 5 indicates that maturity achieved the highest increment $(1.00 \%)$ in EQ percentage. Empathy reported the highest decrement (2.44\%). The other domains showed percentage decreases. 


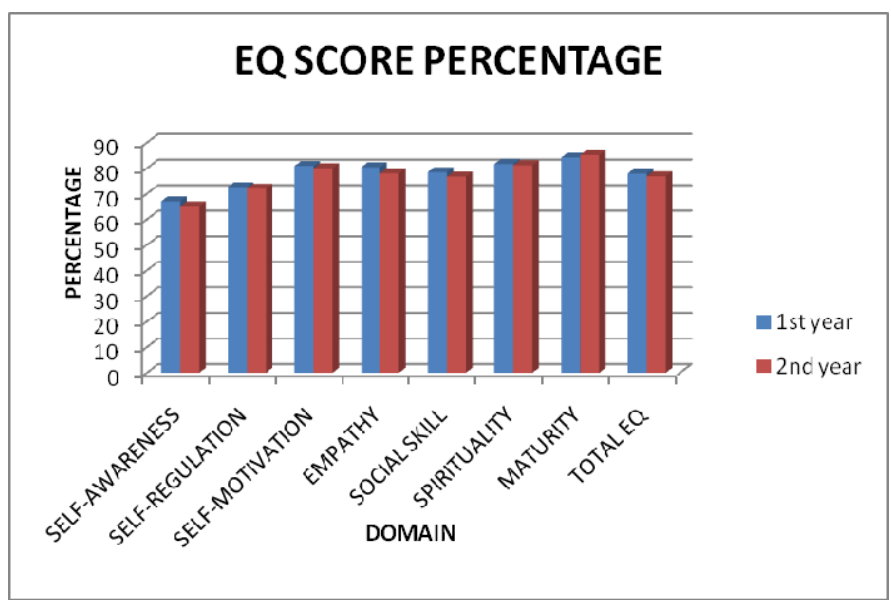

Figure 5. Comparison between the EQ percentage of second year students in their first year of enrollment and their EQ percentage in their second year of enrollment

Table 2 indicates no positive increase in EQ percentage for students who have graduated as well as the fourth year, third year, and second year students. These students obtained decrements of $0.09 \%, 1.40 \%, 0.01 \%$, and $1.02 \%$, respectively, in total EQ percentage.

Table 2. Comparison of total EQ percentages among all student groups

\begin{tabular}{lc}
\hline Groups & Total EQ \% development \\
\hline First group: First year and graduation level & -0.09 \\
Second group: First year and fourth year & -1.40 \\
Third group: First year and third year & -0.01 \\
Fourth group: First year and second year & -1.02 \\
\hline
\end{tabular}

The results indicate a positive development in social skills and maturity domains for the first group, which consists of students who have completed their four-year academic program. The outcomes for this group are significant because they indicate the EQ level of students who have graduated and who will enter the job market. EQ evaluation helps enhance the portfolio and marketability of a fresh graduate in a job market with high academic achievers.

The increase in social skills domain from the $60 \%$ range to the upper $70 \%$ range suggests that the students recognized the value of their four-year academic experience in enhancing their social skills. This may have resulted from their participation in individual and group presentations to satisfy course requirements. Graduating students were also required to complete a final-year project, which may be an experiment, a survey, or a case study. This project entails two presentations of their proposed project and a final presentation evaluated by lecturers. Completion of such a requirement normally takes one year. Thus, students make appointments and interact with other people who can contribute to their research. The students develop their communication skills as they interact with people from various companies and organizations. In addition, students need to communicate with their appointed lecturer, who also acts as their supervisor, for advice, guidance, and support. Another learning element that may have strengthened the social skills domain of students is the industrial training undergone by students in their third year of enrollment. The experience they gained may have helped them improve their communication skills and capability in managing issues and problems while studying.

UKM students come from various races, respecting one another. They cooperate with one another to accomplish group projects, as well as engage in brainstorming sessions and group meetings, which are among the most effective ways of solving problems. The social skills development in the tertiary level can be attributed to co curricular programs and social activities despite these programs being voluntary and not compulsory such as oral presentations in academic courses.

Likewise, the increase in the maturity domain percentage is expected from the test results. As students progress and mature during the four years of study, their anticipation of various situations develop, which allows them to adapt more appropriately and respond to changes compared with their first year of enrollment.

The percentage decline obtained by the other domains may be attributed to the grueling experience of completing the final year. The final year is normally considered the last opportunity for students to improve their 
overall academic performance. The effort exerted to achieve this objective may have affected the other EQ domains, resulting in neglect in terms of development. For example, the self-awareness of the students who have graduated is different from that of the second year students because the former are already focused on entering the job market. The total EQ for exit-level students slightly decreased because of the percentage reduction in other domains.

This study presented and interpreted the MEQI test results of Engineering and Built Environment students. An extended research is required to determine the reasons for the increase or decrease in the EQ scores for appropriate intervention programs to be developed.

\section{Conclusions}

The use of the MEQI test can determine the general EQ levels of new and graduating students. The results can be used in developing modules to strengthen the weak domains. Modules can be designed by incorporating certain skills into each assessment method for every course in the faculty. The skills include conflict management, interpersonal communication, empowerment in communication, and public speaking. Significant improvement will benefit engineering students, especially in verbalizing their opinions and speaking confidently in front of other people. The MEQI test results of the engineering students can help identify inadequacies and make heuristic improvement to help them survive in a multifaceted environment and compete with other people for different opportunities.

Students need to develop a high EQ level although the aforementioned skills are considered secondary to the primary objective of tertiary education, which is to accomplish academic knowledge transfer. High EQ levels help students increase their value in the job market, as well as project exceptional leadership and managerial skills. This study should be extended by acquiring data on the academic performance of students at the end of every academic year. The purpose is to determine whether a correlation exists between student EQ levels and academic achievements. The effectiveness of each initiative in increasing EQ levels according to the domains that constitute the model also requires close monitoring.

\section{Acknowledgments}

The authors would like to acknowledge the financial support received from the Centre for Engineering Education Research, Universiti Kebangsaan Malaysia under the research grants PTS-2011-014 and OUP-2012-126 in improving the quality of teaching and learning in the field of engineering.

\section{References}

Bar-On, R. (1997). BarOn Emotional Quotient Inventory: Technical Manual. Toronto: Multi-Health Systems.

Boyatzis, R. E., \& Sala, F. (2004). The Emotional Competence Inventory (ECI). See Geher 2004.

Goleman, D. (1995). Emotional Intelligence. New York: Bantam.

Janovicz, J., \& Christiansen, N. D. (2001). Emotional intelligence at the workplace. Paper presented at the 16th Annual Conference of the Society of Industrial and Organizational Psychology, San Diego, CA, April.

Lyubomirsky, S., King, L., \& Diener, E. (2005). The benefits of frequent positive affect: Does happiness lead to success? Psychol. Bull 131. http://dx.doi.org/10.1037/0033-2909.131.6.803

Mandler, G. (1975). Mind and Emotion. New York: Wiley.

Noriah, M. I., \& Zuria, M. (2003). Kepintaran Emosi di Kalangan Pekerja di Malaysia. Prosiding IRPA- RMK-8 Kategori EAR. Jilid 1, 184-187.

Petrides, K. V., \& Furnham, A. (2001). Trait emotional intelligence: psychometric investigation with reference to established trait taxonomies. Eur. J. Personal, 15, 425-448. http://dx.doi.org/10.1002/per.416

Prakash, S., Peter, M., \& Raj. M. (2007). Importance of emotional intelligence in conceptualizing collegial leadership in education. South African Journal of Education, 27, 541-563

Salovey, P., \& Mayer, J. D. (1990). Emotional intelligence. Imagination, Cognition, and Personality, 9, 185-211. http://dx.doi.org/10.2190/DUGG-P24E-52WK-6CDG

Schmidt-Atzert, L., \& Bühner, M. (2002). Entwicklung eines Leistungstests zur Emotionalen Intelligenz: 43. Kongress der Deutschen Gesellschaft für Psychologie, Berlin.

Tett, R. P., Fox, K. E., \& Wang, A. (2005). Development and validation of a self-report measure of emotional intelligence as a multidimensional trait domain. Personal. Soc. Psychol. 
Van der Zee, K. I., Thijs, M., \& Schakel, L. (2002). The relationship of emotional intelligence with academic intelligence and the big five. European Journal of Personality, 16, 103-125. http://dx.doi.org/10.1002/per.434 